\title{
Common Mental Disorder and early interruption of exclusive maternal breastfeeding in Quilombola women: a population-based study
}

\author{
Vanessa Gabrielle dos Santos Araújo 1 \\ iD https://orcid.org/0000-0003-3818-2551 \\ Tamara Rodrigues dos Santos 2 \\ iD https://orcid.org/0000-0001-5439-7910 \\ Ana Carolina Santana Vieira 3 \\ iD https://orcid.org/0000-0002-7273-1414 \\ Monica Lopes de Assunção 4 \\ iD https://orcid.org/0000-0003-2985-9890 \\ Haroldo da Silva Ferreira 5 \\ iD https://orcid.org/0000-0002-1789-3138
}

\footnotetext{
1 Programa de Pós-Graduação em Nutrição. Faculdade de Nutrição. Universidade Federal de Alagoas.Maceió, AL, Brasil.

2 Programa de Pós-Graduação em Ciências da Saúde. Universidade Federal de Alagoas. Maceió, AL, Brasil.

${ }^{3}$ Escola de Enfermagem. Universidade Federal de Alagoas. Maceió, AL, Brasil.

4,5 Faculdade de Nutrição. Universidade Federal de Alagoas.Campus A.C. Simões - BR 104, km 14. Tabuleiro dos Martins. Maceió, AL, Brasil.CEP: 57.072-970. E-mail: haroldo.ufal@gmail.com
}

\begin{abstract}
Objectives: to investigate the prevalence of exclusive maternal breastfeeding (EMBF) and evaluate whether common mental disorder (CMD) and other predictors promote its early interruption (EI-EMBF4).

Methods: a cross-sectional study involving all children $<24$ months $(n=252)$ residing in $50 \%(n=34)$ of the Quilombola communities in Alagoas. The EI-EMBF4 was established when EMBF was $\leq 4$ months. The Self-Reporting Questionnaire was used to identify the occurrence of CMD. Other predictors were obtained through interviews. The measure of association was the prevalence ratio calculated by the Poisson regression, following a hierarchical theoretical model. The prevalence of EMBF for 4 and 6 months, and its median duration (survival analysis) were calculated.

Results: the prevalence of EI-EMBF4 and CMD was $57.6 \%$ and $42.9 \%$, respectively. The risk factors independently associated with EI-EMBF4 were: living in a mud house, maternal age $\leq 18$ years, low birth weight and the use of a pacifier or baby bottle. There was no association with CMD. The prevalence of EMBF for four and six months was $42.4 \%$ and $25.4 \%$, respectively, and the median duration was 106 days.

Conclusion: EMBF indicators are below the established recommendations, justifying the implementation of measures that prioritize women subjected to risk factors identified here. $C M D$ is not configured among these.

Key words Maternal breastfeeding, Epidemiology, Mental health, Mental disorders, African Continental ancestry group
\end{abstract}

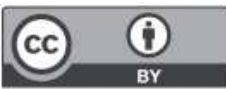




\section{Introduction}

Despite the consensus that exclusive maternal breastfeeding (EMBF) during the first six months of life is the healthiest way to feed the infant, studies conducted in Brazil show that this goal has rarely been achieved, despite investments by national and international institutions. ${ }^{1,2}$

Several factors may contribute to the early interruption of EMBF, and many of them are related to the mother, such as low levels of schooling and family income, work outside the home during the puerperium, primiparity, and young age. ${ }^{3}$

Socioeconomic, cultural, and psychological variables are related to the time a mother spends breastfeeding and may affect this process positively or negatively. In this regard, the desire and determination of the mother to breastfeed is a decisive factor for the success of this activity. Therefore, the potential negative effect that disorders related to maternal mental health could have on the intention and willingness to breastfeed is a matter of concern. These disorders are part of a category of conditions called common mental disorders (CMD), also known as non-psychotic disorders, a condition characterized by the occurrence of anxiety, depressive, and psychosomatic symptoms. 4,5

The prevalence of CMD is higher in women who are separated or widowed, have children, are black or mixed skin color, have low schooling, live in precarious housing conditions, have low income and are unemployed. ${ }^{6}$ These factors are mostly present in women belonging to Quilombola communities, which are formed by African slaves descendants and are characterized by high socioeconomic vulnerability and low access to public services. ${ }^{7}$ However, no previous study has investigated if there is an association between Quilombola women's mental health and the practice of breastfeeding.

The objectives of this study were: a) to investigate some indicators related to EMBF (prevalence by 4 and 6 months; median time at EMBF) in children under 24 months of age from the Quilombola population in Alagoas; $b$ ) to identify the prevalence and to analyze if maternal CMD is associated with the early interruption of EMBF and; c) to identify the risk factors for early interruption of EMBF.

\section{Methods}

This is a cross-sectional study, which is part of a project called "Nutrição e saúde da população materno-infantil das comunidades remanescentes dos quilombos do estado de Alagoas" (Nutrition and health of the maternal and child population of the remaining Quilombola communities in Alagoas State) (Projeto Quilombola), which was approved by the Research Ethics Committee of the Universidade Federal de Alagoas (process number 33527214.9.0000.5013). All mothers or legal guardians of the investigated children were duly informed about the study and, after agreeing to participate, signed the Informed Consent Form.

According to the list of the Quilombola communities with official certification (http://www.iteral.al.gov.br/dtpaf/comunidadesquilombolas-de-alagoas/comunidades-quilombolasde-alagoas), there were 68 communities in Alagoas in 2017, in which about 6,889 families resided.

For the sample planning of the Projeto Quilombola, the family was considered as the unit of analysis. Due to the diversity of objectives proposed in this study, a prevalence of $50 \%$ was considered for all outcomes of interest, ensuring the largest possible sample size and thus, with sufficient statistical power to analyze all the variables according to the different objectives. A total of 2,635 families would be necessary for a sampling error of $2.0 \%$ and a $95 \%$ confidence interval. In order to accomplish this, this work intended to investigate the universe of families residing in $50 \%$ of the Quilombola communities in Alagoas State. Using the systematic sampling strategy, 34 communities were chosen from the 68 existing ones, which were distributed in 27 of the 102 cities in Alagoas, mostly located between the Agreste (Harsh desert) and Sertão (Hinderland) regions in this State. The estimate was that 3,108 families lived in the selected communities.

All the children under 24 months of age residing in these communities, as well as their mothers, were eligible. Non-biological children and children and/or mothers who, at the time of birth, presented conditions that prevented the practice of breastfeeding were excluded from this investigation.

The data collection was carried out from April 2017 to January 2018 and was conducted by interviewers (professionals and undergraduate students, both from the health area) properly trained and supervised. During home visits, the interviews were conducted with mothers following a script of questions printed on forms previously tested in a pilot study.

The fieldwork in each community was preceded by contact with local leaders to obtain logistical support and publicize the research, in order to facilitate adherence by the community.

The dependent variable was the early interruption of EMBF (EI-EMBF4), defined here as occur- 
ring before the fourth month of life. In order to structure the variable, the mother was asked "Until what age <child's name> received only breast milk, without receiving water, tea, juice, milk or any other type of liquid or food?" To increase the reliability of the answer obtained, in a subsequent question, the mother was asked "At what age, in addition to breastfeeding, <child's name $>$ also began to receive tea, water, juice, or any other type of food?"

When there was disagreement, the interviewer read the two questions and their respective answers again, and the mother was asked if she had understood the questions correctly, with the explanation being detailed when necessary. Then, the questions were rephrased, and the consensual answer was used to characterize the EI-EMBF4. To calculate the prevalence of this indicator, children younger than 4 months and still on EMBF $(n=16)$ were excluded from the analysis. However, those who had already abandoned this practice were considered. Thus, the final sample analyzed consisted of 236 children.

In addition to these questions, we applied the food consumption markers form from the Ministry of Health, 8 and also the 24-hour recall dietary survey, in which the mother reported the child's food intake on the previous day, which was applied by a nutritionist or a nutrition course student. Thus, if the mother reported that the child "only breastfeeds," but the questionnaire or 24-hour recall showed consumption of any food other than breast milk, the child was not considered to be on EMBF.

Despite the recommendation that EMBF should be extended until the sixth month of life, we chose to study a shorter period (4 months) because the sample exposed to EMBF for six months was small $(n=58)$ and thus, with low statistical power for the necessary analyses. However, in addition to the fourmonth prevalence of EMBF, the prevalence was also calculated for the six-month period to allow future comparisons. In addition to the prevalence calculation, the median duration of time in EMBF was estimated. It is important to clarify that, contrary to what was done to calculate the prevalence of EMBF for 4 or 6 months (or, alternatively, the EI-EMBF4), in which children below these ages who were still breastfeeding were excluded from this analysis, these children remained in the calculation of the median duration of EMBF, since the statistical procedure used allowed us to correct this estimate (survival analysis).

The independent variable (maternal CMD) was established by applying the Self-Reporting Questionnaire (SRQ-20) screening tool, which is made of twenty questions with dichotomous answers (yes/no) about the emotional and physical symptoms associated with non-psychotic conditions. Its score corresponds to a range of 0 to 20 , in which each "yes" answer is equivalent to 1 point. A study conducted in Pernambuco identified that the best cut-off point to identify possible cases of CMD was $\geq 6$ points. Considering the high similarity with this population, we chose to use this same classification criterion in this study. 5 Additionally, aiming to investigate the effect of the magnitude of the score obtained by the mother on the SRQ at the time the child remained on EMBF, the scale of this instrument was divided by three, establishing three categories: from 0 to 6 , from 7 to 13 , and from 14 to 20 points (lower, middle, and upper thirds).

In addition to the dependent and independent variables, covariates were used to control the potentially confounding effects in the relationship between CMD and EMBF and to identify other variables associated with EI-EMBF4. For this, a hierarchical theoretical model adapted from Victora et al. ${ }^{9}$ was used, as illustrated in Figure 1. The variables that comprised the model were:

Socioeconomic and environmental: Economic class according to the criteria established by the Associação Brasileira de Empresas de Pesquisa (ABEP) ${ }^{10}$ (Brazilian Association of Research Companies), which classifies families in descending order of economic level: A, B, C, and D+E. Due to the absence of families belonging to the highest stratum, the variable was analyzed dichotomously $(\mathrm{B}+\mathrm{C} ; \mathrm{D}+\mathrm{E})$; Family beneficiary of the Bolsa Família Program (yes; no); Predominant construction material in the household (masonry; mud), occupation regime of the household (owned; financed/leased/rented) and; Number of people per household $(\leq 4 ;>4)$.

Maternal characteristics: Parity (primiparous; multiparous), Age group ( $\leq 18$ years; $>18$ years); Marital status (married/living with partner; single/separated/widow); Schooling, in years of study $(\leq 8 ;>8)$; Occupation outside the home (yes; no); Self-reported skin color (black; white), being categorized as black for those who declared themselves as black or mixed skin color (other situations such as indigenous or yellow were not reported); Positive CMD (yes; no).

Prenatal, delivery, and postpartum characteristics: Had prenatal care (yes; no); Gestational age at the beginning of prenatal care $(\leq 3$ months; $>3$ months); Number of prenatal visits $(<6 ; \geq 6)$; Breastfeeding counseling during prenatal care (yes; no); Type of delivery (vaginal; cesarean/other); and Breastfeeding within the first hour after childbirth 
(yes; no).

Child characteristics: Sex (male; female); the child's skin color reported by the mother (black/mixed; white/yellow); Gestational age at birth $(<37 ; \geq 37)$; Low birth weight $(<2,500 \mathrm{~g})$; Use of pacifier (yes; no); and Baby bottle use (yes; no).

The data were entered in independent double entry in Epi-info form, version 3.5.4. After comparing the two files and correcting the typing errors, the database for statistical analysis was created using Stata software, version 12.0.

A total of 272 children and their mothers were evaluated. However, those children whose mothers did not answer the SRQ form were excluded from the analysis $(n=20 ; 7.3 \%)$, totaling a sample formed by 252 mother/child binomials.

The descriptive analysis was performed for the socioeconomic, environmental, maternal, and children variables. The bivariate analysis was performed to compare the frequencies of EI-EMBF4 according to CMD and the covariates using the Pearson's Chisquare test. The measure of association was the prevalence ratio (PR) and its respective $95 \%$ confidence interval (CI95\%), being calculated using the Poisson regression with robust adjustment of variance, both in the gross and adjusted analyses. In the latter, the variables that in the crude analysis were associated with early EMBF discontinuation were introduced at a $20 \%$ significance level $(p<0.2)$.
In the hierarchical analysis, at each level of the theoretical model, the variables that presented the lowest level of significance (highest $p$-value) were gradually excluded (backward elimination). In the final model, only those that reached statistical significance $(p<0.05)$ at their respective level remained in the model. Significant variables from more distal levels were inserted and maintained as adjustment variables, respectively, in the following hierarchical levels, remaining in the final model even if they have lost significance in analyses after their original level.

The variables that composed the hierarchical model were:

a) At the distal level: socioeconomic and environmental variables;

b) At the distal intermediate level: maternal characteristics;

c) At the proximal intermediate level: prenatal, delivery, and postpartum characteristics;

d) At the proximal level: child-related characteristics.

To determine the prevalence of EMBF for four and six months, the total of children under 24 months was analyzed. However, children aged less than six and four months, respectively, whose mothers reported that they were still on EMBF were not included in the analyses because it was impossible to know how long the child would remain on this diet to reach the respective goals of 4 or 6

\section{Figure 1}

Hierarchical model on the relationships between the risk factors for early cessation of exclusive maternal breastfeeding.

\section{Distal level \\ (Socioeconomic and envi- ronmental variables)}

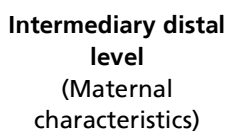
Intermediary proximal level (Prenatal, childbirth and post- partum characteristics)

\section{Proximal level \\ (Child's \\ characteristics)}

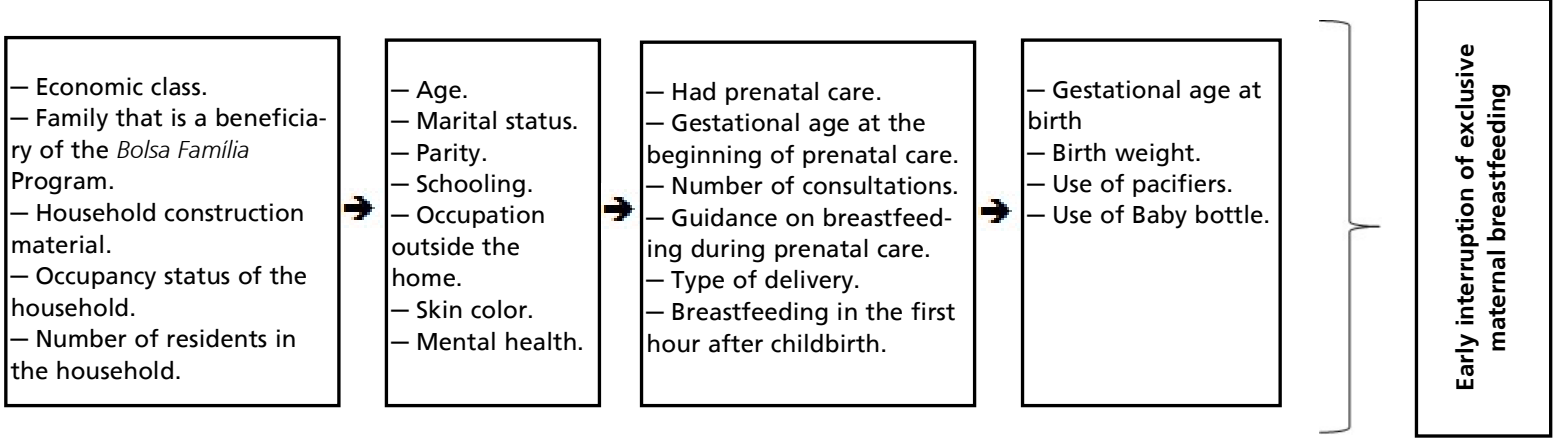

Adapted from Victora et al.9 
months on EMBF. However, the children in these age groups who had already stopped EMBF were included in the calculation to define the variable "early interruption of EMBF".

The median duration of EMBF was calculated by survival analysis using the Kaplan-Meier curves. This analysis involved all the children in the sample $(\mathrm{n}=252)$.

The Kolmogorov-Smirnov test was used to check for the normality of the distribution of time in days for the occurrence of EI-EMBF4. Since the data did not adhere to the parametric assumptions, the Kruskall-Wallis test was used to compare the medians relative to the time of the occurrence of EIEMBF4, according to the mothers' classification in the categories established based on the thirds of the SRQ scores.

\section{Results}

A total of 252 children and their mothers were investigated. Most families belonged to D+E economic classes $(n=243 ; 96.4 \%)$ and were beneficiaries of the Bolsa Família Program $(n=205 ; 81.4 \%)$. The other socioeconomic and environmental characteristics are described in Table 1.

Regarding the maternal variables, most were over 18 years old $(n=226 ; 89.7 \%)$, had no occupation outside the home $(\mathrm{n}=189 ; 76.2 \%)$, and had attended school for up to eight years $(n=130$; $51.8 \%$ ).

As for the gestational data, 248 mothers (98.8\%) reported having prenatal care, most of them started in the first trimester of pregnancy $(n=188 ; 77.1 \%)$ and were attended more than six consultations $(\mathrm{n}=177 ; 74.4 \%)$, during which they received guidance on breastfeeding $(n=213 ; 85.5 \%)$. About three fourths $(n=169 ; 75.8 \%)$ of the infants were breastfed within the first hour after childbirth.

The majority of the children were black or mixed skin color $(n=195 ; 77.7 \%)$. Only $6.7 \%(n=15)$ were born underweight and $93.3 \%(n=234)$ were born at term (gestational age $\geq 37$ weeks). Pacifier was reported by $40.6 \%(n=102)$ of the mothers while $67.7 \%(n=170)$ used a baby bottle.

The prevalence of the children under 24 months receiving EMBF for at least four or six months was $42.4 \%(\mathrm{n}=100)$ and $25.4 \%(\mathrm{n}=58)$, respectively. The prevalence of EI-EMBF4 was $57.6 \%(n=136)$. The median duration of this variable was 106 days.

The prevalence of CMD was $42.9 \%(n=108)$ and this condition was not associated with early EMBF interruption (Figure 2). The analysis according to the thirds of the SRQ scale score distribution also showed no association. The prevalence of EIEMBF4 according to the 1 st, $2^{\text {nd }}$, and 3 rd thirds were $57.6 \%, 57.6 \%$, and $57.9 \%$, respectively. The median number of days until the interruption of the EMBF also showed no significant difference according to these thirds: $75.0,90.0$, and $89.5(p=0.51$ by Kruskal-Wallis test).

In the crude analysis, the covariates that were associated with EI-EMBF4 were the following: residing in a mud house $(\mathrm{PR}=1.79 ; \mathrm{CI} 95 \%=1.60$ $2.01 ; p<0.001)$, maternal age group $\leq 18$ years $(\mathrm{PR}=1.41 ; \mathrm{CI} 95 \%=1.10-1.81 ; \mathrm{p}=0.006)$, less than six prenatal visits $\quad(\mathrm{PR}=1.20 ; \quad \mathrm{CI} 95 \%=0.95-1.52$; $p=0.117)$, male $\quad(\mathrm{PR}=1.15 ; \quad \mathrm{CI} 95 \%=0.93-1.44$; $p=0.184)$, born less than 37 weeks ( $\mathrm{PR}=1.39$; $\mathrm{CI} 95 \%=1.03-1.87 ; p=0.028)$, presenting low birth weight $(\mathrm{RP}=1.73 ; \mathrm{CI} 95 \%=1.43-2.08 ; p<0.001)$, and those that used a pacifier $(\mathrm{PR}=1.41$; CI95\% $=1.14$ $1.75 ; p=0.001)$ and baby bottle $(\mathrm{PR}=2.15$; CI95\% $=1.50-3.09 ; p<0.001)$.

The multivariate analysis (Table 2) showed that the covariates independently associated with early breastfeeding cessation were the following: residing in a mud house ( $\mathrm{PR}=1.56$; $\mathrm{CI} 95 \%=1.24-1.99$; $p<0.001)$, maternal age group $\leq 18$ years $(\mathrm{PR}=1.32$; $\mathrm{CI95 \%}=1.03-1.70 ; p=0.027)$; low birth weight $(\mathrm{PR}=1.43 ; \mathrm{CI} 95 \%=1.13-1.81 ; p=0.002)$, use of pacifier $(\mathrm{PR}=1.29$; $\mathrm{CI} 95 \%=1.03-1.61 ; p=0.025)$, and use of baby bottle ( $\mathrm{PR}=2.14$; CI95\%=1.41-3.25; $p<0.001)$.

\section{Discussion}

The families investigated are distinguished from other population segments by their outstanding social vulnerability, since almost all of them (96.4\%) belong to the lowest economic class, a much higher proportion than that observed in the Brazilian population $(28.3 \%)^{10}$ and for the population in Alagoas (51.2\%), even though this is one of the poorest States in the federation. ${ }^{11}$ Consistent with this context, it is noteworthy the great dependence that these families have on welfare policies, particularly on the Bolsa Familia Program, a federal cash transfer program that covers more than $80 \%$ of this population.

In this study, the prevalence of EMBF for four months was $42.4 \%$, reducing to $25.4 \%$ when the six months were considered. The benefits resulting from exclusive breastfeeding are widely recognized by the scientific community12 however, despite the recommendation of the World Health Organization (WHO) on the ideal time for EMBF and the existence of national public policies aimed to promote this practice, the prevalence of EMBF is still below the 
Characterization of early interruption of exclusive maternal breastfeeding - EMBF (absolute and percentage frequency, prevalence ratio - PR and C195\%) according to socioeconomic, environmental, and variables related to pregnancy care and mothers and children's health under two years of age $(n=252)$ in the Quilombola communities in Alagoas, Brazil, 2018.

\begin{tabular}{|c|c|c|c|c|c|c|}
\hline \multirow[t]{2}{*}{ Variables } & \multirow[t]{2}{*}{$\mathrm{Na}$} & \multirow[t]{2}{*}{$\%$} & \multicolumn{3}{|c|}{ Early interruption of EMBF } & \multirow[t]{2}{*}{$p^{b}$} \\
\hline & & & $\mathrm{n}$ & $\%$ & PR $(\mathrm{Cl} 195 \%)$ & \\
\hline \multicolumn{7}{|l|}{ Household material } \\
\hline Mud & 10 & 4.0 & 10 & 100.0 & $1.79(1.60-2.01)$ & $<0.001 *$ \\
\hline Masonry & 242 & 96.0 & 126 & 55.7 & 1 & \\
\hline \multicolumn{7}{|l|}{ Occupation regime } \\
\hline Financed/Leased/Rented & 40 & 15.9 & 24 & 63.2 & $1.11(0.85-1.46)$ & 0.428 \\
\hline Owned & 212 & 84.1 & 112 & 56.6 & 1 & \\
\hline \multicolumn{7}{|l|}{ Residents in the household } \\
\hline$>4$ people & 102 & 40.5 & 53 & 56.4 & $0.96(0.76-1.20)$ & 0.755 \\
\hline$\leq 4$ people & 150 & 59.5 & 83 & 58.4 & 1 & \\
\hline \multicolumn{7}{|l|}{ Family beneficiary of the $B o l s a$} \\
\hline \multicolumn{7}{|l|}{ Familia Program } \\
\hline No & 47 & 18.6 & 23 & 53.5 & $0.91(0.67-1.23)$ & 0.559 \\
\hline Yes & 205 & 81.4 & 113 & 58.5 & 1 & \\
\hline \multicolumn{7}{|l|}{ Social class ABEP } \\
\hline $\mathrm{B} 2+\mathrm{C} 1+\mathrm{C} 2$ & 9 & 3.6 & 5 & 55.6 & $0.96(0.53-1.74)$ & 0.900 \\
\hline $\mathrm{D}+\mathrm{E}$ & 243 & 96.4 & 131 & 57.7 & 1 & \\
\hline \multicolumn{7}{|l|}{ Maternal age group } \\
\hline$\leq 18$ years & 26 & 10.3 & 18 & 78.3 & $1.41(1.10-1.81)$ & $0.006 *$ \\
\hline$>18$ years & 226 & 89.7 & 118 & 55.4 & 1 & \\
\hline \multicolumn{7}{|l|}{ Maternal marital status } \\
\hline Single, widow or separated & 39 & 15.5 & 21 & 58.3 & $1.01(0.75-1.37)$ & 0.906 \\
\hline Married/lives with partner & 212 & 84.5 & 114 & 57.3 & 1 & \\
\hline \multicolumn{7}{|l|}{ Maternal schooling } \\
\hline$\leq 8$ years & 130 & 51.8 & 73 & 59.3 & $1.07(0.85-1.33)$ & 0.539 \\
\hline$>8$ years & 121 & 48.2 & 62 & 55.4 & 1 & \\
\hline \multicolumn{7}{|l|}{ Occupation outside the home } \\
\hline Yes & 59 & 23.8 & 33 & 58.9 & $1.00(0.78-1.29)$ & 0.957 \\
\hline No & 189 & 76.2 & 103 & 58.5 & 1 & \\
\hline \multicolumn{7}{|c|}{ Mother's skin color (self-declared) } \\
\hline White & 27 & 10.8 & 13 & 52.0 & $0.88(0.59-1.31)$ & 0.554 \\
\hline Black or Mixed & 224 & 89.2 & 123 & 58.6 & 1 & \\
\hline \multicolumn{7}{|c|}{ Maternal common mental disorder } \\
\hline Yes & 108 & 42.9 & 59 & 59.0 & $1.04(0.83-1.29)$ & 0.714 \\
\hline No & 144 & 57.1 & 77 & 56.6 & 1 & \\
\hline \multicolumn{7}{|l|}{ Parity } \\
\hline Primiparous & 100 & 40.4 & 54 & 58.1 & $1.02(0.81-1.28)$ & 0.841 \\
\hline Multiparous & 149 & 59.6 & 80 & 56.7 & 1 & \\
\hline \multicolumn{7}{|l|}{ Prenatal } \\
\hline No & 3 & 1.2 & 1 & 33.3 & $0.57(0.11-2.85)$ & 0.497 \\
\hline Yes & 248 & 98.8 & 135 & 58.2 & 1 & \\
\hline \multicolumn{7}{|l|}{ Beginning of prenatal (in months) } \\
\hline$>$ 3th quarter & 56 & 22.9 & 32 & 61.5 & $1.08(0.84-1.39)$ & 0.533 \\
\hline$\leq 3^{\text {th }}$ quarter & 188 & 77.1 & 100 & 56.8 & 1 & \\
\hline
\end{tabular}


Characterization of early interruption of exclusive maternal breastfeeding - EMBF (absolute and percentage frequency, prevalence ratio - PR and C195\%) according to socioeconomic, environmental, and variables related to pregnancy care and mothers and children's health under two years of age $(n=252)$ in the Quilombola communities in Alagoas, Brazil, 2018.

\begin{tabular}{|c|c|c|c|c|c|c|}
\hline \multirow[t]{2}{*}{ Variables } & \multirow[t]{2}{*}{$\mathrm{Na}$} & \multirow[t]{2}{*}{$\%$} & \multicolumn{3}{|c|}{ Early interruption of EMBF } & \multirow[t]{2}{*}{$p^{b}$} \\
\hline & & & $\mathrm{n}$ & $\%$ & PR $(\mathrm{Cl} 95 \%)$ & \\
\hline \multicolumn{7}{|c|}{ Number of prenatal consultations } \\
\hline$<6$ & 61 & 25.6 & 37 & 66.1 & $1.20(0.95-1.52)$ & 0.117 \\
\hline$\geq 6$ & 177 & 74.4 & 91 & 54.8 & 1 & \\
\hline \multicolumn{7}{|c|}{ Guidance on breastfeeding during } \\
\hline \multicolumn{7}{|l|}{ prenatal care } \\
\hline No & 36 & 14.5 & 17 & 50.0 & $0.85(0.59-1.21)$ & 0.373 \\
\hline Yes & 213 & 85.5 & 117 & 58.8 & 1 & \\
\hline \multicolumn{7}{|l|}{ Type of delivery } \\
\hline Cesarean section & 115 & 45.8 & 67 & 60.4 & $1.08(0.87-1.34)$ & 0.465 \\
\hline Normal & 136 & 54.2 & 69 & 55.6 & 1 & \\
\hline \multicolumn{7}{|c|}{ Breastfeeding in the 1 st hour after birth } \\
\hline No & 54 & 24.2 & 28 & 53.8 & $0.94(0.70-1.25)$ & 0.693 \\
\hline Yes & 169 & 75.8 & 89 & 57.0 & 1 & \\
\hline \multicolumn{7}{|l|}{ Child's sex } \\
\hline Male & 120 & 47.6 & 69 & 62.2 & $1.15(0.93-1.44)$ & 0.184 \\
\hline Female & 132 & 52.4 & 67 & 53.6 & 1 & \\
\hline \multicolumn{7}{|c|}{ Child's skin color (reported by the mother } \\
\hline \multicolumn{7}{|l|}{ or legal responsible) } \\
\hline Black or brown & 195 & 77.7 & 103 & 56.6 & $0.90(0.71-1.16)$ & 0.446 \\
\hline Others & 56 & 22.3 & 33 & 62.3 & 1 & \\
\hline \multicolumn{7}{|c|}{ Gestational age at birth } \\
\hline$<37$ weeks & 17 & 6.7 & 11 & 78.6 & $1.39(1.03-1.87)$ & $0.028^{*}$ \\
\hline$\geq 37$ weeks & 234 & 93.3 & 125 & 56.3 & 1 & \\
\hline \multicolumn{7}{|l|}{ Weight at birth $(g)$} \\
\hline$<2,500$ & 15 & 6.7 & 14 & 93.3 & $1.73(1.43-2.08)$ & $<0.001$ * \\
\hline$\geq 2,500$ & 209 & 93.3 & 106 & 54.1 & 1 & \\
\hline \multicolumn{7}{|l|}{ Use of a pacifier } \\
\hline Yes & 102 & 40.6 & 66 & 70.2 & $1.41(1.14-1.75)$ & $0.001 *$ \\
\hline No & 149 & 59.4 & 70 & 49.6 & 1 & \\
\hline \multicolumn{7}{|l|}{ Use of baby bottle } \\
\hline Yes & 170 & 67.7 & 114 & 68.7 & $2.15(1.50-3.09)$ & $<0.001$ * \\
\hline No & 81 & 32.3 & 22 & 31.9 & 1 & \\
\hline
\end{tabular}

a Number of samples differ in some variables due to non-response cases.

b Wald test.

* Statistically significant difference $(p \leq 0.05)$.

$\mathrm{ABEP}=$ Associação Brasileira de Empresas de Pesquisa. 


\section{Figure 2}

Survival curves, estimated by the Kaplan-Meier method, for the duration of exclusive maternal breastfeeding, according to the occurrence of maternal Common Mental Disorders (CMD) in mothers of children under 24 months of age living in the Quilombola communities in Alagoas. Brazil, 2018.

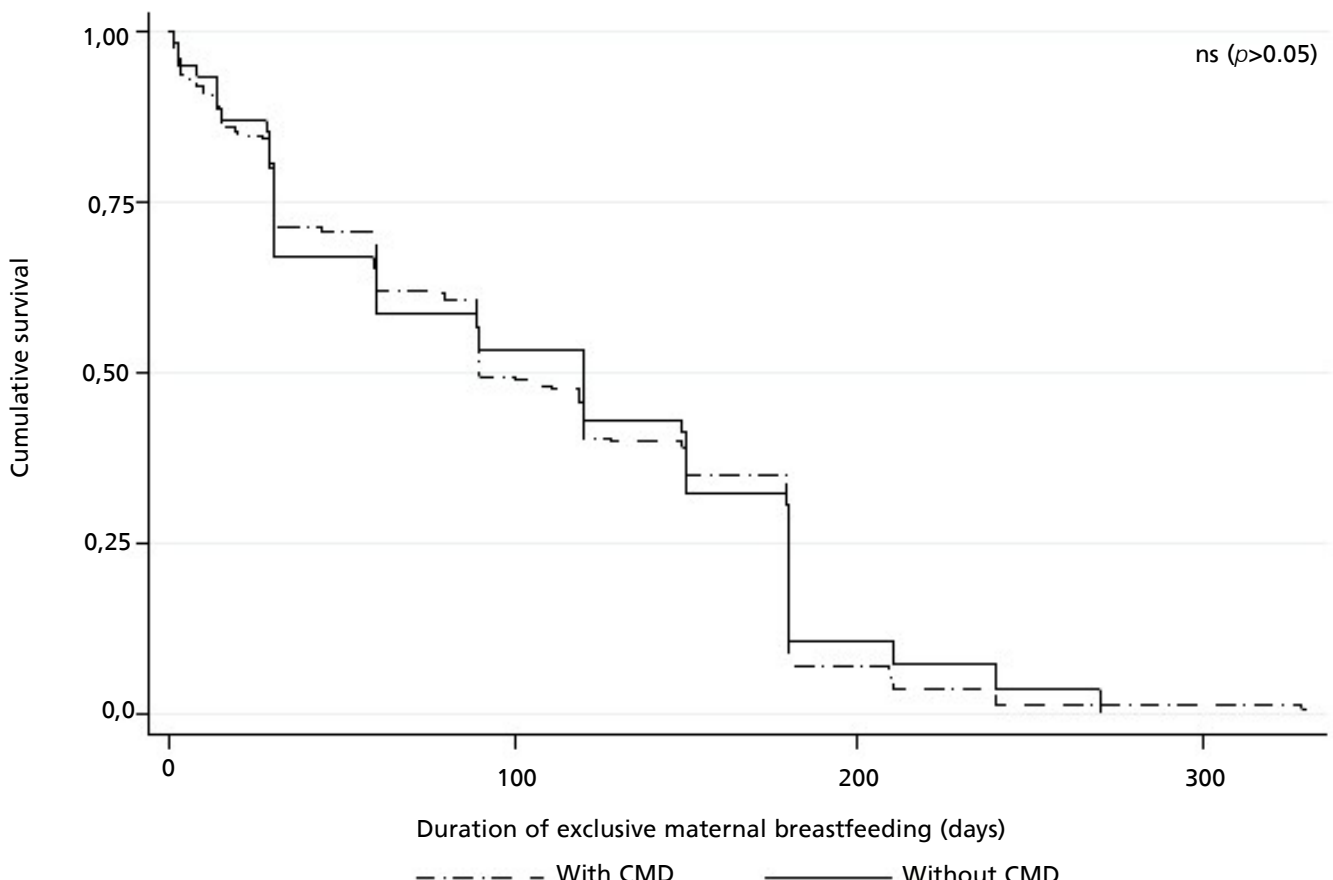

ns = not significant: there was no significant difference at the time of the exclusive maternal breastfeeding according to maternal mental health, defined by the Self-Reporting Questionnaire, a screening tool for common mental disorders.

\section{Table 2}

Early interruption of exclusive maternal breastfeeding (EMBF) in children under 24 months in Quilombola communities in Alagoas: gross ( $P R b)$ and adjusted ( $P R a)$ prevalence ratios after multiple analysis according to the hierarchical conceptual model.

\begin{tabular}{|c|c|c|c|c|}
\hline Variables & PRb (Cl95\%) & $p$ & $\operatorname{PRa}(\mathrm{Cl} 95 \%)$ & pa \\
\hline Household material & & $<0.001$ & & $<0.001$ * \\
\hline Mud & $1.79(1.60-2.01)$ & & $1.56(1.24-1.99)$ & \\
\hline Masonry & 1 & & 1 & \\
\hline Maternal age group (years) & & 0.006 & & $0.027 *$ \\
\hline$\leq 18$ years & $1.41(1.10-1.81)$ & & $1.32(1.03-1.70)$ & \\
\hline$>18$ years & 1 & & 1 & \\
\hline Number of prenatal consultations & & 0.117 & & ns \\
\hline$<6$ & $1.20(0.95-1.52)$ & & $1.14(0.90-1.45)$ & \\
\hline$\geq 6$ & 1 & & 1 & \\
\hline Sex & & 0.184 & & ns \\
\hline Male & $1.15(0.93-1.44)$ & & $1.20(0.96-1.50)$ & \\
\hline Female & 1 & & 1 & \\
\hline
\end{tabular}


Early interruption of exclusive maternal breastfeeding (EMBF) in children under 24 months in Quilombola communities in Alagoas: gross $\left(P^{b}\right)$ and adjusted $\left(P R^{a}\right)$ prevalence ratios after multiple analysis according to the hierarchical conceptual model.

\begin{tabular}{|c|c|c|c|c|}
\hline Variables & PRb (Cl95\%) & $p$ & PRa (CI95\%) & $p^{a}$ \\
\hline Gestational age at birth & & 0.028 & & ns \\
\hline$<37$ weeks & $1.39(1.03-1.87)$ & & $0.98(0.96-1.39)$ & \\
\hline$\geq 37$ weeks & 1 & & 1 & \\
\hline Weight at birth & & $<0.001$ & & $0.002 *$ \\
\hline$<2,500 \mathrm{~g}$ & $1.73(1.43-2.08)$ & & $1.43(1.13-1.81)$ & \\
\hline$\geq 2,500 \mathrm{~g}$ & 1 & & 1 & \\
\hline Use of pacifiers & & 0.001 & & $0.025^{*}$ \\
\hline Yes & $1.41(1.14-1.75)$ & & $1.29(1.03-1.61)$ & \\
\hline No & - & & - & \\
\hline Use of baby bottle & & $<0.001$ & & $<0.001$ * \\
\hline Yes & $2.15(1.50-3.09)$ & & $2.14(1.41-3.25)$ & \\
\hline No & 1 & & 1 & \\
\hline
\end{tabular}

recommended time, a fact observed not only in Brazil but in several other countries. 13

Globally, data released by WHO in 2017,13 show that the prevalence of EMBF in children under six months is $40 \%$. According to the II Breastfeeding Prevalence Survey (II PPAM) in the Brazilian capitals and the Federal District, ${ }^{1}$ conducted in 2008, the prevalence of EMBF among children under six months was $41 \%$, a value higher than that found in the present study $(25.4 \%)$. It is noteworthy that the behavior of this indicator in this study was heterogeneous1, with the highest prevalence $(45.9 \%)$ identified in the North Region and the lowest in the Northeast Region (37.0\%), but still higher than that identified in the present study.

Considering Alagoas State, the prevalence observed in this study was higher than that identified in a survey of children from the semi-arid region of the State, 14 in which the prevalence of EMBF for four months was $28.6 \%$. In Maceió, the capital of Alagoas, this prevalence was $21.6 \%$, according to data from the II PPAM. 1 This fact can be explained by the worst socioeconomic conditions and by a situation of high social vulnerability in which Quilombola children are inserted, corroborating with other studies that indicate higher prevalence among populations subjected to this context. 1,14

The practice of breastfeeding is affected by the mother's historical, cultural, socioeconomic, and psychological factors. All these situations can directly impact the time that the child is breast- feeding. 14,15 The average duration of EMBF in Quilombola children in this study was 106 days. This average is higher than that observed (54.1 days) for all the Brazilian capitals. ${ }^{1}$

The decline in the prevalence of EMBF between the fourth and sixth month (from $42.4 \%$ to $25.4 \%$ ) may be influenced by the high frequency of bottle feeding (67.7\%) in the Quilombola population, a situation associated with the early introduction of other food, especially other types of milk and porridge. This early interruption of EMBF is associated with the offer of other food, which, in this phase of life, may make the child more susceptible to infections and the risk of compromising its growth and development. 16 Vieira et al.17,18 found that not being exposed to EMBF in the first four to six months of life is associated with lower weight and length gain. From this perspective, the importance of actions to prevent the main causes of early interruption of EMBF and the consequent damage to children's health is emphasized. Identifying the risk factors related to this situation can help guide the actions developed in health services aimed at the promotion, protection, and the support of EMBF.

As previously mentioned, the factors that were independently associated with early interruption of EMBF in this study were living in a mud house, maternal age $\leq 18$ years, low birth weight, bottle feeding, and the use of a pacifier.

Almost all the Quilombola families in this study belong to the lowest economic strata $(\mathrm{D}+\mathrm{E})$ and no 
family scored values compatible with class A. Ramos et al. 19 found that mothers living under unfavorable socioeconomic conditions tended to keep breastfeeding their children for a longer period. In this study, this association was not confirmed, probably due to the high homogeneity of the families regarding this variable. However, an association was found between the outcome and the fact that the child lived in a mud house. Thus, considering specific differentials within the community investigated, the greater socioeconomic vulnerability was a risk factor for EI-EMBF4. This finding corroborates to other studies 20,21 that reported higher frequencies of early interruption of EMBF among poorer individuals, attributing this fact to low schooling levels. Being a young mother was also associated with early EMBF interruption. The women's children aged 18 years or younger had a prevalence of $32 \%$ higher than of older mothers. This seems to be associated with the fact that, generally because it is the first child, the mother would present greater difficulty to breastfeed due to the insecurity generated by inexperience, lack of information, and little support from family and/or partner. 22

Regarding to the child's characteristics, the factors associated with the early interruption of EMBF were low birth weight, the use of a pacifier, and bottle feeding.

The use of pacifiers among the Quilombola children investigated in this study was reported by $40.6 \%$ of the mothers. In the II PPAM 1 the use of a pacifier by children younger than twelve months was $42.6 \%$, and this value was slightly higher (44.8\%) in Maceió. The use of pacifier has been associated with difficulties faced by mothers to deal with the children's crying, which make them think that their milk is weak, insufficient and not able to meet their children's needs. This feeling is often the justification for offering other types of milk and/or other food.23

The introduction of bottle-feeding, which requires less sucking effort from the child, impairs the strengthening of oral muscles and conditions the child to incorrect suckling, causing "nipple confusion", which leads the infant to reject the maternal breast. 24

In this study, the use of baby bottle feeding was reported by $67.7 \%$ of the mothers and the prevalence of interruption of EMBF before the sixth month of life was $74.6 \%$. In the II PPAM, it was observed that the use of a baby bottle was $58.4 \%$ in the group of the Brazilian capitals, being $60.0 \%$ in the Northeast region, and $61.0 \%$ in Maceió.

A cohort study carried out in São Luís do Maranhão 25 suggested that babies who use pacifiers and/or baby bottles have a higher rate of conditions (incorrect sucking; nipple confusion) that make breastfeeding difficult when compared to those who did not use these resources.

In this study, the prevalence of CMD among mothers was $42.9 \%$, a value similar to that found in the urban area $(43.8 \%)$ of the semi-arid region in Alagoas. ${ }^{26}$ People with CMD usually report fatigue, forgetfulness, insomnia, irritability, concentration deficit, headaches, in addition to psychosomatic complaints. Its occurrence is higher in women, who do not live with a partner, have children, low income, black or mixed skin color, low schooling, live in precarious housing conditions, and are unemployed. Most of these conditions are particularly present in Quilombola women. 4

A qualitative study conducted with AfricanAmerican women in 2013,27 revealed the existence of personal frustrations that interfered with the ability to breastfeed, negatively affecting this practice due to the stress in managing the responsibilities assigned to women, combined with the lack of support in the postpartum period.

Depression is one of the most common psychological disorders worldwide, affecting 10 to $15 \%$ of all women.28 Some studies indicate the existence of an association between problems related to maternal mental health and the early interruption of EMBF.27, 28 However, in this Quilombola population, this association was not found.

It is important to emphasize that the studies that verified the existence of this relationship were carried out adopting specific criteria to diagnose specific mental health problems. The SRQ-20, used here to classify women according to their mental health, is a screening and not a diagnostic instrument, which addresses different dimensions of CMD and, therefore, cannot be related to a particular outcome. However, this was a limitation of this study, and the hypothesis of the association investigated here cannot be ruled out. New studies on Quilombola communities are suggested, but employing more accurate mental health indicators, because, despite the absence of an association with EMBF, due to its magnitude, the prevalence of CMD reported here $(42.9 \%)$ deserves special consideration.

According to a meta-analysis 29 of 174 publications from 63 countries, $19.7 \%$ of the women had CMD. In Brazil, a population-based study of 848 women in the city of Campinas found that this value was $18.7 \% .30$ These results allow us to state that the prevalence of CMD among Quilombola women is quite high and, considering the damage that this situ- 
ation imposes on the quality of life of these women, 29,30 it is a relevant public health problem that requires special attention from public authorities and health professionals.

In addition to highlighting the epidemiological relevance of CMD, this study has the merit of its robust analytical approach and consistent sampling plan, presenting unprecedented data on the practice of breastfeeding in a population historically neglected and subjected to institutional discrimination, providing higher visibility to the problem of Quilombola people and illustrating the need for greater attention and investment in healthcare and quality of life for this population.

It is important to emphasize that this work presents other limitations, besides the low accuracy of the instrument used to characterize maternal mental health, as already have been mentioned. Among these limitations, there is the retrospective nature by which the information on breastfeeding was obtained, which makes the study prone to memory bias. In addition, there may be no temporal relationship between EMBF and the presence of CMD symptoms, since this condition was obtained at the time of the interview, reflecting a current situation. However, the consistency of the findings based on comparisons with other investigations makes us believe that these biases were not enough to alter the results to such an extent as to compromise the conclusions obtained. Regarding these comparisons, it is important to emphasize the necessity of caution in interpreting the differences in the median EMBF time obtained here with those found in the II PPAM1, the main national study on breastfeeding, because different methodologies were used, although both adequate for the purpose.

Based on the results obtained, it was possible to conclude that:

(a) the prevalence of early interruption of EMBF was high so the time that the child remained under this condition was far below the recommendations by the World Health Organization;

b) The prevalence of maternal CMD was high but did not affect the duration of the EMBF. However, it is not possible to confirm whether this is a characteristic of the Quilombola population or whether it resulted from the low specificity of the instrument used to identify the CMD, which is why it is recommended that the study be reproduced using more accurate indicators in the diagnosis of specific mental health problems;

c) The risk factors independently associated with early interruption of EMBF were the following: living in a mud house, being a teenage mother, low birth weight, and regular use of pacifiers and baby bottles.

The results of this study should be used as a support for the planning and implementation of actions to promote, protect, and support breastfeeding, as well as measures for mental health care, focusing on Brazilian Quilombola communities, especially those located in Alagoas State

\section{Acknowledgements}

To the Conselho Nacional de Desenvolvimento Científico e Tecnológico (CNPq) (National Council for Scientific and Technological Development) and the Fundação de Amparo à Pesquisa do estado de Alagoas (FAPEAL) (Foundation for Research Support of the state of Alagoas) for the financial resources granted for this research. To the students and interns of the Laboratory of Basic and Applied Nutrition of the Faculdade de Nutrição da Universidade Federal de Alagoas, for collecting and entering the data. To the health agents and community leaders for their support during the fieldwork and, especially, to the study population for their receptivity, patience, and time spent during our visits to their homes to conduct the interviews.

\section{Authors' contribution}

Araújo VGS and Santos TR contributed to data collection during fieldwork, data typing and tabulation, analysis and interpretation of results, and writing the preliminary version of the article. Vieira ACS and Assunção ML participated in the analysis and interpretation of the results and the writing of the preliminary version of the paper. Ferreira HS was responsible for writing the project and obtaining funding, overall coordination of the research, interpretation of data, and critical review of the manuscript. All authors participated in writing the final version of the paper and declared their approval for publication. 


\section{References}

1. Brasil. Ministério da Saúde. Secretaria de Atenção à Saúde Departamento de Ações Programáticas e Estratégicas. II Pesquisa de prevalência de aleitamento materno nas capitais brasileiras e Distrito Federal. Brasília, DF; 2009.

2. WHO (World Health Organization). Indicators for assessing infant and young child feeding practices: conclusions of a consensus meeting held 6-8 November 2007 in Washington DC, USA Washington DC, USA; 2008.

3. Pereira-Santos M, Santana MS, Oliveira DS, Nepomuceno Filho RA, Lisboa CS, Almeida LM, et al. Prevalence and associated factors for early interruption of exclusive breastfeeding: meta-analysis on Brazilian epidemiological studies. Rev Bras Saúde Mater Infant. 2017; 17: 59-67.

4. Jansen K, Mondin TC, Ores LC, Souza LD, Konradt CE, Pinheiro RT, et al. Transtornos mentais comuns e qualidade de vida em jovens: uma amostra populacional de Pelotas, Rio Grande do Sul, Brasil. Cad Saúde Pública. 2011; 27 (3) 440-8.

5. Ludermir AB, Melo Filho DA. Condições de vida e estrutura ocupacional associadas a transtornos mentais comuns Rev Saúde Pública. 2002; 36: 213-21.

6. Araújo TM, Pinho PS, Almeida MM. Prevalência de transtornos mentais comuns em mulheres e sua relação com as características sociodemográficas e o trabalho doméstico. Rev Bras Saude Mater Infant. 2005; 5: 337-48.

7. Ferreira HS, Silva WO, Santos EA, Bezerra MK, Vieira da Silva BC, Horta BL. Body composition and hypertension: a comparative study involving women from maroon communities and from the general population of Alagoas State, Brazil. Rev Nutr. 2013; 26 (5): 539-49.

8. Brasil. Ministério da Saúde. Secretaria de Atenção à Saúde Departamento de Atenção Básica. Orientações para avaliação de marcadores de consumo alimentar na atenção básica. Brasília, DF; 2015.

9. Victora CG, Huttly SR, Fuchs SC, Olinto M. The role of conceptual frameworks in epidemiological analysis: a hierarchical approach. Int J Epidemiol. 1997; 26 (1): 224-7.

10. ABEP (Associação Brasileira de Empresas de Pesquisa). Critério de Classificação Econômica Brasil. Alterações na aplicação do Critério Brasil. São Paulo; 2019.

11. Costa NS, Santos MO, Carvalho CPO, Assunção ML, Ferreira HS. Prevalence and Factors Associated with Food Insecurity in the Context of the Economic Crisis in Brazil Curr Dev Nutr. 2017; 1 (10): e000869.

12. Del Ciampo LA, Del Ciampo IRL. Breastfeeding and the Benefits of Lactation for Women's Health. Rev Bras Ginecol Obstet. 2018; 40 (6): 354-9.

13. UNICEF, World Health Organization. Global Breastfeeding Scorecard, 2017: Tracking Progress for Breastfeeding Policies and Programmes. New York; 2017.

14. Ferreira HS, Vieira ED, Queiroz MD, Cabral Junior CR. Aleitamento materno por trinta ou mais dias é fator de

Received on July 8, 2020

Final version presented on December 14, 2020

Approved on February 18, 2021 proteção contra sobrepeso em pré-escolares da região semiárida de Alagoas. Rev Assoc Med Bras. 2010;56 (1): 74-80.

15. Rocha GP, Oliveira MC, Ávila LB, Longo GZ, Cotta RM, Araújo RM. Condicionantes da amamentação exclusiva na perspectiva materna. Cad Saúde Pública. 2018; 34 (6): e00045217.

16. Margotti E, Mattiello R. Risk factors for early weaning. Rev RENE. 2016; 17 (4): 537-44.

17. Vieira FS, Costa ES, Sousa GC, Oliveira TMP, Neiva MJLM. Influência do parto sobre o desmame no puerpério. Rev Pesq Cuid Fundam. 2019; 11: 425-31.

18. Vieira SA, Magalhães TCA, Ribeiro AQ, Priore SE, Franceschini SCC, Sant'Ana LFR. Fatores associados às velocidades de ganho de peso e de comprimento nos primeiros seis meses de vida. Cad Saúde Coletiva. 2015; 23 (3): $309-15$

19. Ramos CV, Almeida JA, Alberto NS, Teles JB, Saldiva SR. Diagnóstico da situação do aleitamento materno no Estado do Piauí, Brasil. Cad Saúde Pública. 2008; 24 (8): 1753-62.

20. Santos PV, Martins MC, Tapety FI, Paiva AA, Fonseca FM, Brito AK. Desmame precoce em crianças atendidas na Estratégia Saúde da Família. Rev Eletr Enf. 2018; 20.

21. Faleiros FTV, Trezza EMC, Carandina L. Aleitamento materno: fatores de influência na sua decisão e duração. Rev Nutr. 2006; 19 (5): 623-30.

22. Maranhão TA, Oliveira Gomes KR, Nunes LB, Moura LNB. Fatores associados ao aleitamento materno exclusivo entre mães adolescentes. Cad Saúde Coletiva. 2015; 23 (2): 132-9.

23. Araújo CM, Silva GA, Coutinho SB. A utilização da chupeta e o desenvolvimento sensório motor oral. Revista CEFAC. 2009; 11 (2): 261-7.

24. Rigotti RR, Oliveira MI, Boccolini CS. Associação entre o uso de mamadeira e de chupeta e a ausência de amamentação no segundo semestre de vida. Ciênc Saúde Coletiva. 2015; 20: 1235-44.

25. Batista CL, Ribeiro VS, Desterro SB, Rodrigues VP. Association between pacifier use and bottle-feeding and unfavorable behaviors during breastfeeding. J Pediatr. 2018; 94 (6): 596-601

26. Paffer AT, Ferreira HS, Cabral Júnior CR, Miranda CT. Prevalence of common mental disorders in mothers in the semiarid region of Alagoas and its relationship with nutritional status. São Paulo Med J. 2012; 130 (2): 84-91.

27. Johnson AM, Kirk R, Rooks AJ, Muzik M. Enhancing breastfeeding through healthcare support: Results from a focus group study of African American mothers. Matern Child Health J. 2016; 20 (1): 92-102.

28. Brecailo MK, Saldan PC. Relação entre depressão materna e os cuidados em saúde à criança: revisão sistemática. UNOPAR Ciênc Biol Saúde. 2013; 15 (Esp): 423-9.

29. Steel Z, Marnane C, Iranpour C, Chey T, Jackson JW, Patel $\mathrm{V}$, et al. The global prevalence of common mental disorders: a systematic review and meta-analysis 1980-2013. Int J Epidemiol. 2014; 43 (2): 476-93.

30. Senicato C, Azevedo RC, Barros MB. Transtorno mental comum em mulheres adultas: identificando os segmentos mais vulneráveis. Ciênc Saúde Coletiva. 2018; 23: 254354. 